\title{
The burden and spatial distribution of bovine African trypanosomes in small holder crop- livestock production systems in Tororo District, south-eastern Uganda
}

Dennis Muhanguzi ${ }^{1,2^{*}}$, Kim Picozzi $^{2}$, Jan Hattendorf ${ }^{3,4}$, Michael Thrusfield $^{5}$, John David Kabasa ${ }^{6}$, Charles Waiswa ${ }^{7}$ and Susan Christina Welburn ${ }^{2}$

\begin{abstract}
Background: African animal trypanosomiasis (AAT) is considered to be one of the greatest constraints to livestock production and livestock-crop integration in most African countries. South-eastern Uganda has suffered for more than two decades from outbreaks of zoonotic Human African Trypanosomiasis (HAT), adding to the burden faced by communities from AAT. There is insufficient AAT and HAT data available (in the animal reservoir) to guide and prioritize AAT control programs that has been generated using contemporary, sensitive and specific molecular techniques. This study was undertaken to evaluate the burden that AAT presents to the small-scale cattle production systems in south-eastern Uganda.

Methods: Randomised cluster sampling was used to select 14\% (57/401) of all cattle containing villages across Tororo District. Blood samples were taken from all cattle in the selected villages between September-December 2011; preserved on FTA cards and analysed for different trypanosomes using a suite of molecular techniques. Generalized estimating equation and Rogen-Gladen estimator models were used to calculate apparent and true prevalences of different trypanosomes while intra cluster correlations were estimated using a 1-way mixed effect analysis of variance (ANOVA) in R statistical software version 3.0.2.

Results: The prevalence of all trypanosome species in cattle was $15.3 \%(95 \% \mathrm{Cl} ; 12.2-19.1)$ while herd level trypanosome species prevalence varied greatly between 0-43\%. Trypanosoma vivax $(17.4 \%, 95 \% \mathrm{Cl}$; $10.6-16.8)$ and Trypanosoma brucei rhodesiense (0.03\%) were respectively, the most, and least prevalent trypanosome species identified.

Conclusions: The prevalence of bovine trypanosomes in this study indicates that AAT remains a significant constraint to livestock health and livestock production. There is need to implement tsetse and trypanosomiasis control efforts across Tororo District by employing effective, cheap and sustainable tsetse and trypanosomiasis control methods that could be integrated in the control of other endemic vector borne diseases like tick-borne diseases.
\end{abstract}

Keywords: African animal trypanosomiasis, Human african trypanosomiasis, Control, ITS1-PCR, Prevalence, Tororo district

\footnotetext{
*Correspondence: luckydenno@covab.mak.ac.ug

'Department of Biomolecular and Biolaboratory Sciences, School of

Biosecurity, Biotechnical and Laboratory Sciences, College of Veterinary

Medicine Animal Resources and Biosecurity, Makerere University, P.O. Box

7062, Kampala, Uganda

${ }^{2}$ Division of Infection \& Pathway Medicine, Centre for Infectious Diseases,

School of Biomedical Sciences, College of Medicine and Veterinary Medicine,

The University of Edinburgh, Chancellor's Building, 49 Little France Crescent,

Edinburgh EH16 4SB, UK

Full list of author information is available at the end of the article
}

\section{Ciomed Central}

(c) 2014 Muhanguzi et al.; licensee BioMed Central. This is an Open Access article distributed under the terms of the Creative Commons Attribution License (http://creativecommons.org/licenses/by/4.0), which permits unrestricted use, distribution, and reproduction in any medium, provided the original work is properly credited. The Creative Commons Public Domain Dedication waiver (http://creativecommons.org/publicdomain/zero/1.0/) applies to the data made available in this article, unless otherwise stated. 


\section{Background}

African Animal Trypanosomiasis (AAT) is one of the most important vector-borne diseases of livestock in East Africa and common throughout the tsetse belts of Africa $[1,2]$. Trypanosoma congolense, Trypanosoma vivax and Trypanosoma brucei subspecies brucei are the most important causes of AAT mainly transmitted by tsetse flies (Glossina ssp.) [3]. AAT is usually chronic; characterized by loss of condition, progressive anaemia and often terminates in death if untreated [4]. T. vivax can also be transmitted mechanically by broad spectra of haematophagous insects and as a result, AAT caused by $T$. vivax has been recorded outside of the tsetse belts [5]. T. brucei rhodesiense and T.b. brucei are less pathogenic in cattle than $T$. congolense and T. vivax [5]. The persistent and long-term presence of T. brucei rhodesiense in cattle as a reservoir of human infection is of major public health importance [6] with spillover from domestic livestock causing human T.b. rhodesiense African trypanosomiasis (HAT), also known as sleeping sickness [7-9]. Domestic animals of epidemiological importance, are, notably cattle, which act as reservoirs of the human infective trypanosomes [10-12].

In Sub-Saharan Africa and south-eastern Uganda in particular, vector-borne diseases notably AAT constrain livestock production and compound poverty levels contributing to $34 \%$ of all livestock keepers to subsist on less than 1.24 USD per day [13-15]. Poor livestock health as a result of AAT denies farmers the opportunity to use draft power and manure as the gateway to croplivestock enterprise integration thereby extending this problem of poverty and hunger in the tsetse-infested areas [1,2]. Hunger continues to affect more than one third of the populations in this region $[16,17]$.

There is little contemporary data available on AAT burden generated from the sensitive and specific molecular techniques that are widely available. Such data is essential for guiding and prioritising tsetse control and the integration of such control efforts with those of other endemic vector-borne diseases such as tick-borne diseases (TBDs). The present study represents the first large scale attempt to generate reliable prevalence data from which to evaluate the extent to which the African trypanosomiasis presents a problem in small scale cattle production systems in south-eastern Uganda. A cross sectional survey was undertaken to determine both the prevalence and spatial distribution of African trypanosomes across Tororo District.

\section{Methods}

\section{Study area}

The survey was carried out in Tororo during the period September to December 2011. Tororo District is bordered by the districts of Mbale to the north, Manafwa to the north-east, Busia to the south, Bugiri to the south-west,
Butaleja to the north-west and the Republic of Kenya to the east. The location, farming system, climate and vegetation of the study area have been previously described [18-20]. Cattle are the main tsetse hosts in Tororo district [11,12] contributing up to $54 \%$ of all tsetse blood meals with the rest taken from pigs and monitor lizards (Varanus niloticus) [12]. Glossina fuscipes fuscipes and G. pallidipes are the main tsetse fly species in the district [12]. At the time of the study, the district had estimated cattle population of 37,345 in 401 villages (average $=93$ cattle/village) [21]. There was no evidence of any mass treatment of cattle against AAT in Tororo District between 2010-2011.

\section{Study design and sampling methods}

A cross sectional study was carried out involving taking of blood samples from all cattle in 57 of the 401 cattle containing villages of Tororo District. The cluster sampling methodology [22,23] implemented in C Survey version 2.0 [24] was used to determine the minimum number of clusters needed. Cluster sampling allows variation in the number of clusters and cattle that are sampled (e.g., some cattle in all clusters, all cattle in all clusters; all cattle in some clusters) to achieve the specified parameters. Owing to the large size of this survey, village selection was done by simple random sampling to reduce sampling errors that often result from inherent variability between different samples drawn from a large population (sampling frame). The sampling frame; comprising a complete list of all villages and their georeferenced positions in Tororo District was obtained from the Coordinating Office for Control of Trypanosomiasis in Uganda (COCTU) and verified for completeness at Tororo District lands and planning offices.

Sample size was determined assuming a mean cattle population of 93 cattle per village [21], anticipated prevalence of AAT of $30 \%$ based on the experience of the investigators, and some published general trypanosome studies [25], the precision of the sample estimate (one half-length of the $95 \%$ confidence interval) of 5 percentage points and an intracluster correlation coefficient (ICC) of 0.15. The ICC estimate was based on reported rates of homogeneity (rho) for trypanosomiasis prevalence, noting high variability $[26,27]$. The number of cattle expected to be sampled per cluster was taken as the mean of the number of cattle per village in Tororo District (93). In total, fifty seven (57) clusters (villages) were needed to achieve the set level of precision for trypanosome prevalence estimation. The number of clusters selected fulfil the sampling assumption that the cluster means are normally distributed [28] indicating that a minimum of 30 clusters could have been used.

Infectious diseases (both vector-borne and non-vectorborne) display heterogeneity within a population; that is, 
they tend to cluster into epidemiological units; a group of animals that is of epidemiological significance in terms of the transmission and maintenance of infection, and therefore of disease control. For this reason, the sampling units/clusters for this study are villages; the epidemiological units for trypanosomiasis. A livestock containing village in Tororo District is here defined as a cluster because, in communal husbandry obtaining this is the epidemiological unit.

\section{Cattle blood sample collection}

About $125 \mu \mathrm{l}$ of blood was collected from the middle ear vein and applied onto a designated sample area of the classic Flinders Technology Associates $\left(\mathrm{FTA}^{\circ}\right)$ cards (Whatman Bioscience, Cambridge, UK), avoiding cross contamination $[29,30]$. Blood samples were then allowed to air-dry, labelled with village name, parish, sub county, county and date of collection. They were packed in foil pouches with a silica gel desiccant (Sigma Aldrich, Co., Life sciences, USA) prior to shipping to the University of Edinburgh, UK for analysis.

\section{DNA extraction}

DNA was extracted and eluted in Chelex ${ }^{\circ} 100$ resin (Sigma Aldrich, Co., Life sciences, USA) from five $3 \mathrm{~mm}$ FTA sample discs according to a previously described protocol $[30,31]$. Eluted DNA samples were kept at $-20^{\circ} \mathrm{C}$ for long term PCR analyses or $4^{\circ} \mathrm{C}$ if they were to be analysed within a few days after extraction.

\section{Trypanosome DNA detection}

Eluted DNA samples were screened for different trypanosome species using a single pair of primers (CR and $\mathrm{BR})$ previously designed to amplify internal transcribed spacer (ITS1) of trypanosome ribosomal deoxyribonucleic acid (rDNA) and thermo cycling conditions as previously described [32]. The ITS1- PCR was carried out in a $25 \mu \mathrm{l}$ reaction volume; $20 \mu \mathrm{l}$ of which was the PCR master mix and either $5 \mu \mathrm{l}$ of the test sample or negative control eluate or positive control DNA. The master mix was made of 10x-reaction buffer $(670 \mathrm{mM}$ Tris- $\mathrm{HCl} \mathrm{pH}$ 8.8, $166 \mu \mathrm{M}$ (NH4) ${ }_{2} \mathrm{SO}_{4}, 4.5 \%$ Triton X-100, $2 \mathrm{mg} / \mathrm{ml}$ gelatin) (Fisher Biotech), $1.0 \mathrm{mM} \mathrm{MgCl}$, $200 \mu \mathrm{M}$ of each dNTP, $5 \mu \mathrm{M}$ each of the CF and BR primers, 0.5U of Taq DNA polymerase (Fisher Biotech) and $15.2 \mu \mathrm{l}$ RNase-free molecular grade water.

To determine which samples were infected with either T. brucei or T. b. rhodesiense, multiplex PCR [33] was carried out on each of the samples from which a $450 \mathrm{bp}$ fragment was detected on ITS1-PCR. Multiplex PCR was carried out in $25 \mu \mathrm{l}$ reactions using primers and conditions as previously described [33]

To determine the commonest T.congolense genotype circulating in Tororo District, all samples from which a $\geq 600$ bp fragment was amplified on ITS1-PCR were initially tested for T.congolense savannah using a single pair of primers (TCS1 \& TCS2) and thermo cycling conditions as previously described [34]. All samples that were positive for T.congolense DNA on ITS1-PCR were positive for T.congolense savannah. For this reason, no more $T$. congolense genotype-specific (kilifi, tsavo, forest) PCRs were performed although a few co-infections with different T.congolense genotypes could have been possible. The PCR was carried out in a $25 \mu \mathrm{l}$ reaction volume; $20 \mu \mathrm{l}$ of which was the PCR master mix and either $5 \mu \mathrm{l}$ of the test sample or negative control eluate or positive control DNA. The master mix was made of $10 x$-reaction buffer $\left(670 \mathrm{mM}\right.$ Tris- $\mathrm{HCl} \mathrm{pH}$ 8.8, $166 \mu \mathrm{M}(\mathrm{NH} 4)_{2} \mathrm{SO}_{4}, 4.5 \%$ Triton X-100, $2 \mathrm{mg} / \mathrm{ml}$ gelatin) (Fisher Biotech),, 4.5\% Triton X-100, $2 \mathrm{mg} / \mathrm{ml}$ gelatin) (Fisher Biotech), $0.75 \mathrm{mM}$ $\mathrm{MgCl}_{2}, 200 \mu \mathrm{M}$ of each dNTP, $12.5 \mu \mathrm{M}$ each of the TCS1 \& TCS2 primers, 1U of Taq DNA polymerase (Fisher Biotech) and $13.05 \mu \mathrm{l}$ of RNase-free water.

PCR products for the three sets of PCRs were separated in 1.5\% agarose (Bio Tolls Inc. Japan), stained in GelRed $^{\text {tw }}$ (Biotium, Inc., USA) and visualised on an ultraviolet transilluminator for fragment size determination

\section{Statistical analysis}

Apparent prevalences and their confidence intervals were estimated using the generalized estimating equation models to adjust for correlations within communities. True prevalences were calculated using the Rogen-Gladen estimator. Intra cluster correlations were estimated using a 1-way mixed effect ANOVA model. All statistical analyses were performed using the $\mathrm{R}$ statistical software version 3.0.2. ArcMap v10.3 was used to map prevalence estimates in different villages.

\section{Ethical clearance}

This study was reviewed by the Makerere University College of Veterinary Medicine Animal Resources and Biosecurity ethical review board for compliance to Animal use and Care standards. It was then forwarded to the Uganda National Council for Science and Technology and approved under approval number HS1336.

\section{Results}

Demographic characteristics of the study population

Six thousand fifty four blood samples were taken from all cattle in 57 villages in Tororo District. The mean number of cattle per village was 106 (4-232). The mean number of cattle per household was 4 . The demographic characteristics of the study population are summarized in Table 1. Almost all the animals belonged to the Boran $\times$ short horn Zebu cross-breed. Approximately half of the population were female. 
Table 1 Description of the animal population

\begin{tabular}{lll}
\hline Study population attributes & \multicolumn{2}{l}{ Attribute level (N=6054) } \\
\cline { 2 - 3 } & Sampled (n) & $\%$ \\
\hline a) Age & 1205 & 19.9 \\
$0-12$ months & 1264 & 20.9 \\
13-24months & 953 & 15.7 \\
25-36months & 2632 & 43.5 \\
$>36$ months & & \\
b) Sex & 3117 & 51.5 \\
Female & 2568 & 42.4 \\
Male & 369 & 6.1 \\
Neutered & & \\
c) Breed & 5869 & 96.9 \\
Boran $\times$ short horn Zebu cross & 89 & 1.5 \\
Boran $\times$ Holstein Friesian cross & 96 & 1.6 \\
African short horn Zebu (Nkedi) & & \\
\hline
\end{tabular}

\section{Bovine trypanosome species prevalence}

Out of 6,054 cattle sampled, 850 were infected with a single trypanosome species and a further 78 animals had mixed trypanosome infections (Table 2). The most common co-infections observed were T. vivax and T. b. brucei (37 animals) and $T$. vivax and $T$. congolense (34 animals). The overall prevalence of different trypanosome species was $15.3 \%$ (95\% CI; 12.2-19.1\%). T.brucei s.l. constituted the smallest proportion of trypanosomes in cattle in Tororo District.

\section{Herd level prevalence of different bovine trypanosome species}

There was a very large variation in the prevalence of different trypanosome species between different villages (clusters) with some villages recording 0 infection rates while others recording very high infection rates of up to $43 \%$ (Table 3). As a result, the rate of homogeneity (roh)/ intra-cluster correlation coefficient (ICC) for any trypanosome infection was estimated at 0.11 . The most common trypanosome species was $T$. vivax with an apparent prevalence of 13.4 (10.6-16.8) occurring in 52 out of 57 communities respectively. T. c. savannah and T.brucei s.l. were detected in 53\% and 35\% of all villages sampled. T.b. rhodesiense was detected only in 2 of the 57 (3.5\%) villages sampled.

\section{Prevalence of T.brucei s.I}

Only 69 blood samples were positive for T.brucei s.l. (Figure 1). Further characterisation by multiplex PCR identified 2 of the 69 samples as positive for the human infective $T . b$. rhodesiense. The two $T . b$. rhodesiense positive samples were from the villages of ChawoloSironga B and Kadanya; one positive sample from each of the two villages

\section{Spatial distribution of bovine trypanosomes}

The lowest prevalences were registered along the Kenyan Border while the highest prevalences were recorded in villages in the northern and the western parts of the district bordering the districts of Manafwa and Mbale (Figure 2).

\section{Discussion}

To determine the burden and spatial distribution of African trypanosomes in crop-livestock production systems in Tororo District, south-eastern Uganda, cattle blood samples were taken and tested for different trypanosomes between September and December 2011. Six thousand and fifty four cattle blood samples from 57 villages were analysed for different trypanosomes. The overall prevalence for different trypanosomes in Tororo District of $15.3 \%$ (95\% CI; 12.2-19.1\%) was comparable to those previously reported in this region [12,35]. Individual species prevalences were higher than those reported in previous studies $[12,35]$. The most pathogenic species for cattle, T. vivax and $T$. congolense were recorded at $13.4 \%$ (95\% CI; $10.6-$ $16.8)$ and $2.1 \%$ (95\% CI; 1.4-3.1) respectively. T. brucei s.l was observed at a prevalence of $1.1 \%$ (95\% CI; 0.7-1.8) with a low frequency [36] with 2 of 69 positive samples being positive for $S R A$ gene, indicative of human infectivity [10].

Table 2 Prevalence of different trypanosome species in Tororo district (September- November 2011)

\begin{tabular}{|c|c|c|c|c|c|}
\hline Trypanosome species & Positive/n & Apparent prevalence $^{a}(95 \% \mathrm{Cl})$ & $\%$ True prevalence $^{\mathbf{b}}$ & $\%$ Herd prevalence $^{c}$ & $\mathrm{ICC}^{\mathrm{d}}$ \\
\hline Overall & $928 / 6048$ & $15.3(12.2-19.1)$ & - & 91 & 0.11 \\
\hline T. vivax & $813 / 6053$ & $13.4(10.6-16.8)$ & 17.4 & 91 & 0.09 \\
\hline T. congolense savannah & $127 / 6049$ & $2.1(1.4-3.1)$ & 2.3 & 53 & 0.04 \\
\hline T. b. brucei & $69 / 6050$ & $1.1(0.7-1.8)$ & 1.2 & 35 & 0.02 \\
\hline T. b. rhodesiense & $2 / 6050$ & $0.03(0.0-0.1)$ & 0.03 & 04 & 0.00 \\
\hline
\end{tabular}

${ }^{a}$ Adjusted for intra cluster correlation using generalised estimating equation (GEE) model.

${ }^{\mathrm{b}}$ Rogan-Gladon estimator assuming $100 \%$ specificity and sensitivities of $77.4 \%, 90.9 \%, 95 \%, 95 \%$ for T.vivax, T. c. savannah, T. b. brucei and T. b. rhodesiense [32], respectively.

'Due to the local farming systems, all animals within a certain village are considered as a herd.

${ }^{d}$ Intra cluster correlation coefficient or rate of homogeneity (rho). 
Table 3 Herd level prevalence of different trypanosome species in Tororo district

\begin{tabular}{|c|c|c|c|c|c|c|}
\hline Village & Sampled (n) & All trypanosomes & T. vivax & T.c.savannah & T.brucei s.l. & T.b rhodesiense \\
\hline Adumai & 124 & 0.8 & 0.8 & 0.0 & 0.0 & 0.0 \\
\hline Akadoti & 60 & 20.0 & 16.7 & 3.3 & 0.0 & 0.0 \\
\hline Alupe_A & 66 & 1.5 & 1.5 & 0.0 & 0.0 & 0.0 \\
\hline Alupe_B & 60 & 36.7 & 35.0 & 0.0 & 3.3 & 0.0 \\
\hline Agolol & 163 & 8.6 & 8.6 & 0.0 & 0.0 & 0.0 \\
\hline Asinge-C & 232 & 0.4 & 0.4 & 0.0 & 0.0 & 0.0 \\
\hline Atapara-Kaleu & 160 & 20.6 & 18.1 & 1.9 & 1.2 & 0.0 \\
\hline Biranga-B & 82 & 1.2 & 1.2 & 0.0 & 0.0 & 0.0 \\
\hline Biranga-A & 20 & 35.0 & 25.0 & 10.0 & 5.0 & 0.0 \\
\hline Chawolo_A & 213 & 11.7 & 11.7 & 0.0 & 0.0 & 0.0 \\
\hline Chawolo_B & 188 & 15.4 & 11.7 & 2.7 & 1.6 & 0.5 \\
\hline Dida & 100 & 33.3 & 34.0 & 1.0 & 3.1 & 0.0 \\
\hline East-Central & 56 & 26.8 & 25.0 & 1.8 & 0.0 & 0.0 \\
\hline lyopoki & 86 & 1.2 & 1.2 & 0.0 & 0.0 & 0.0 \\
\hline lyoriang & 118 & 11.9 & 11.0 & 0.0 & 1.7 & 0.0 \\
\hline Kadanya & 132 & 3.8 & 3.8 & 0.0 & 0.0 & 0.8 \\
\hline Kajalau & 64 & 28.1 & 21.9 & 7.8 & 3.1 & 0.0 \\
\hline Kasoli & 197 & 19.8 & 19.8 & 0.0 & 0.0 & 0.0 \\
\hline Katandi & 106 & 13.2 & 12.3 & 0.9 & 0.0 & 0.0 \\
\hline Kateki & 69 & 4.3 & 4.3 & 0.0 & 0.0 & 0.0 \\
\hline Kirewa & 132 & 22.7 & 22.7 & 0.8 & 7.6 & 0.0 \\
\hline Kisera & 101 & 5.9 & 5.9 & 0.0 & 0.0 & 0.0 \\
\hline Kogala & 127 & 3.1 & 2.4 & 0.8 & 0.0 & 0.0 \\
\hline Komolo & 112 & 0.0 & 0.0 & 0.0 & 0.0 & 0.0 \\
\hline Macharimeri & 180 & 38.9 & 36.7 & 2.8 & 4.4 & 0.0 \\
\hline Mailombili & 50 & 20.0 & 16.0 & 4.0 & 0.0 & 0.0 \\
\hline Maliri & 71 & 22.5 & 15.5 & 2.8 & 4.2 & 0.0 \\
\hline Mella & 144 & 0.7 & 0.7 & 0.0 & 0.0 & 0.0 \\
\hline Mikwana & 169 & 21.3 & 19.5 & 5.3 & 0.0 & 0.0 \\
\hline Munyinyi & 164 & 33.7 & 26.4 & 8.5 & 3.0 & 0.0 \\
\hline Mwelo & 36 & 38.9 & 36.1 & 11.1 & 0.0 & 0.0 \\
\hline Ngeta-A & 127 & 18.9 & 18.1 & 0.8 & 0.0 & 0.0 \\
\hline Nyabanja & 139 & 30.9 & 23.0 & 9.4 & 2.9 & 0.0 \\
\hline Nyafumba & 94 & 18.1 & 16.0 & 2.1 & 0.0 & 0.0 \\
\hline Nyemera & 88 & 11.4 & 10.2 & 1.1 & 1.1 & 0.0 \\
\hline Okwira & 18 & 33.3 & 33.3 & 0.0 & 0.0 & 0.0 \\
\hline Opule & 72 & 9.7 & 9.7 & 0.0 & 0.0 & 0.0 \\
\hline Oriyoyi & 124 & 26.6 & 26.6 & 0.0 & 0.0 & 0.0 \\
\hline Osia & 112 & 0.0 & 0.0 & 0.0 & 0.0 & 0.0 \\
\hline Pabasi & 110 & 2.7 & 2.7 & 0.0 & 0.0 & 0.0 \\
\hline Pabendo & 76 & 28.9 & 26.3 & 3.9 & 0.0 & 0.0 \\
\hline Pamaraka & 80 & 18.8 & 11.2 & 8.8 & 0.0 & 0.0 \\
\hline Panyandere & 74 & 1.4 & 1.4 & 0.0 & 0.0 & 0.0 \\
\hline Pasaya & 104 & 21.4 & 16.3 & 7.8 & 0.0 & 0.0 \\
\hline
\end{tabular}


Table 3 Herd level prevalence of different trypanosome species in Tororo district (Continued)

\begin{tabular}{lllllll}
\hline Pawira & 215 & 5.1 & 2.8 & 1.4 & 0.9 & 0.0 \\
Poti & 78 & 6.4 & 6.4 & 0.0 & 0.0 & 0.0 \\
Rubuleri & 91 & 31.9 & 29.7 & 6.6 & 4.4 & 0.0 \\
Rukuli & 32 & 9.4 & 9.4 & 0.0 & 0.0 & 0.0 \\
Segero & 100 & 20.0 & 17.0 & 3.0 & 2.0 & 0.0 \\
Seseme & 52 & 28.8 & 25.0 & 0.0 & 7.7 & 0.0 \\
Sesera & 49 & 42.9 & 24.5 & 18.4 & 4.1 & 0.0 \\
Singisi & 76 & 26.3 & 17.1 & 10.5 & 0.0 & 0.0 \\
Ticaf & 204 & 0.0 & 0.0 & 0.0 & 0.0 & 0.0 \\
Totokidwe & 144 & 25.7 & 24.3 & 1.4 & 2.1 & 0.0 \\
Tuba & 90 & 0.0 & 0.0 & 0.0 & 0.0 & 0.0 \\
Wakasiki & 119 & 29.4 & 22.7 & 2.5 & 0.0 & 0.0 \\
West-Central & 4 & 0.0 & 0.0 & 0.0 & 0.0 & 0.0 \\
\hline
\end{tabular}

The prevalence of different trypanosome species greatly varied between different villages ranging from 0-43\% (Table 3). Villages with medium to high AAT prevalence were clustered along the northern and western borders of Tororo District along the Kenyan border (Figure 2). These areas are mainly covered by forest/savannah vegetation and croplands interspersed with cattle which make the ideal conditions for tsetse infestation. Trypanosome prevalence and land use showed a positive spatial association, which might explain the high prevalences found in the north and western boarders of Kenya (Figure 2). This could be as a result of the differences in tsetse apparent density and veterinary care between villages [37].

T. vivax was detected in $91 \%$ of all sampled villages. Glossina fuscipes fuscipes has been reported to be the commonest tsetse fly species in eastern Uganda [38-40] and was the commonest tsetse species caught in a recent survey at 161 locations in Tororo District [37]. G. f. fuscipes is a better vector for T.vivax than G. pallidipes [37,40], which is scarce despite recent re-invasion in this part of Uganda [35]. This

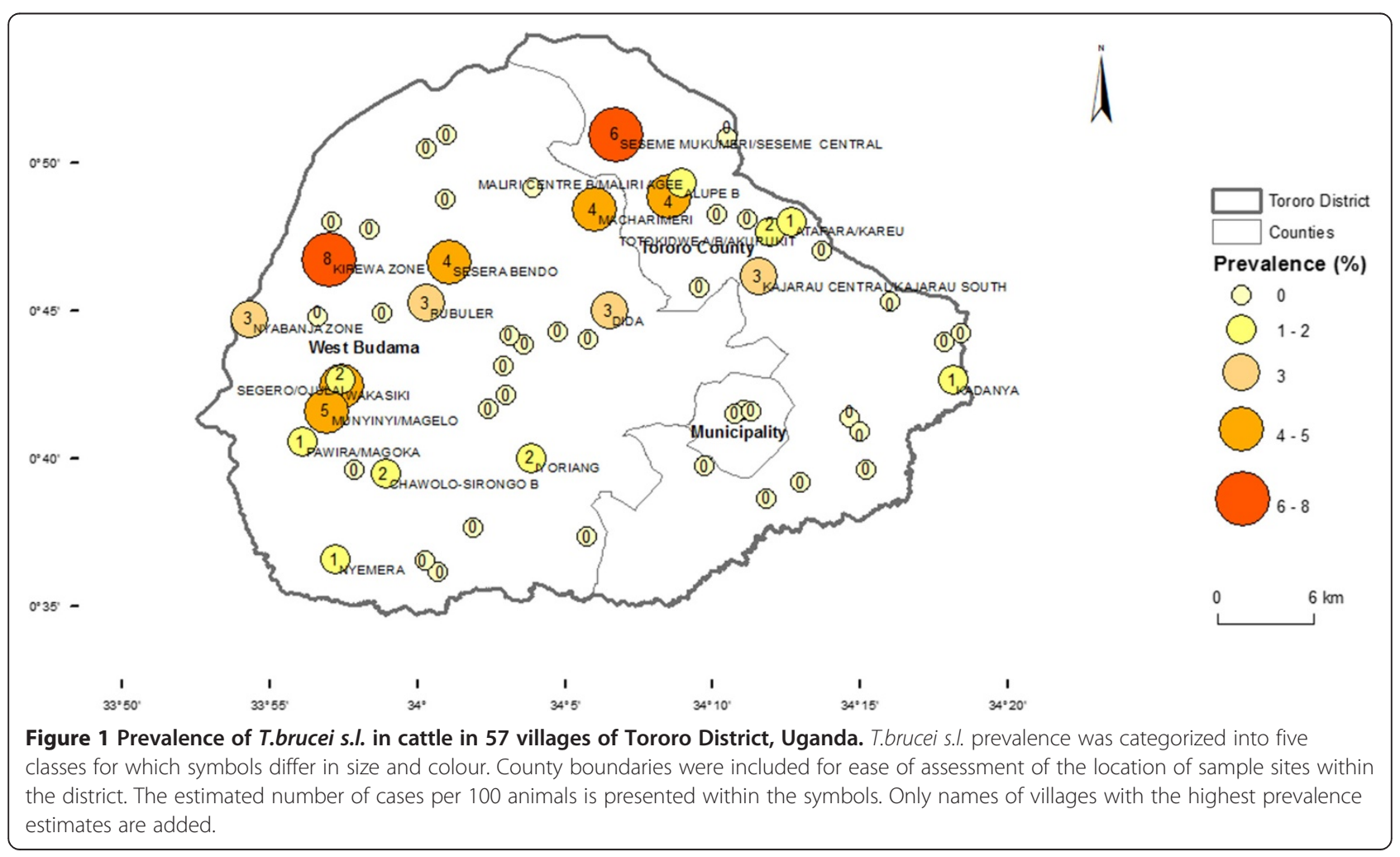




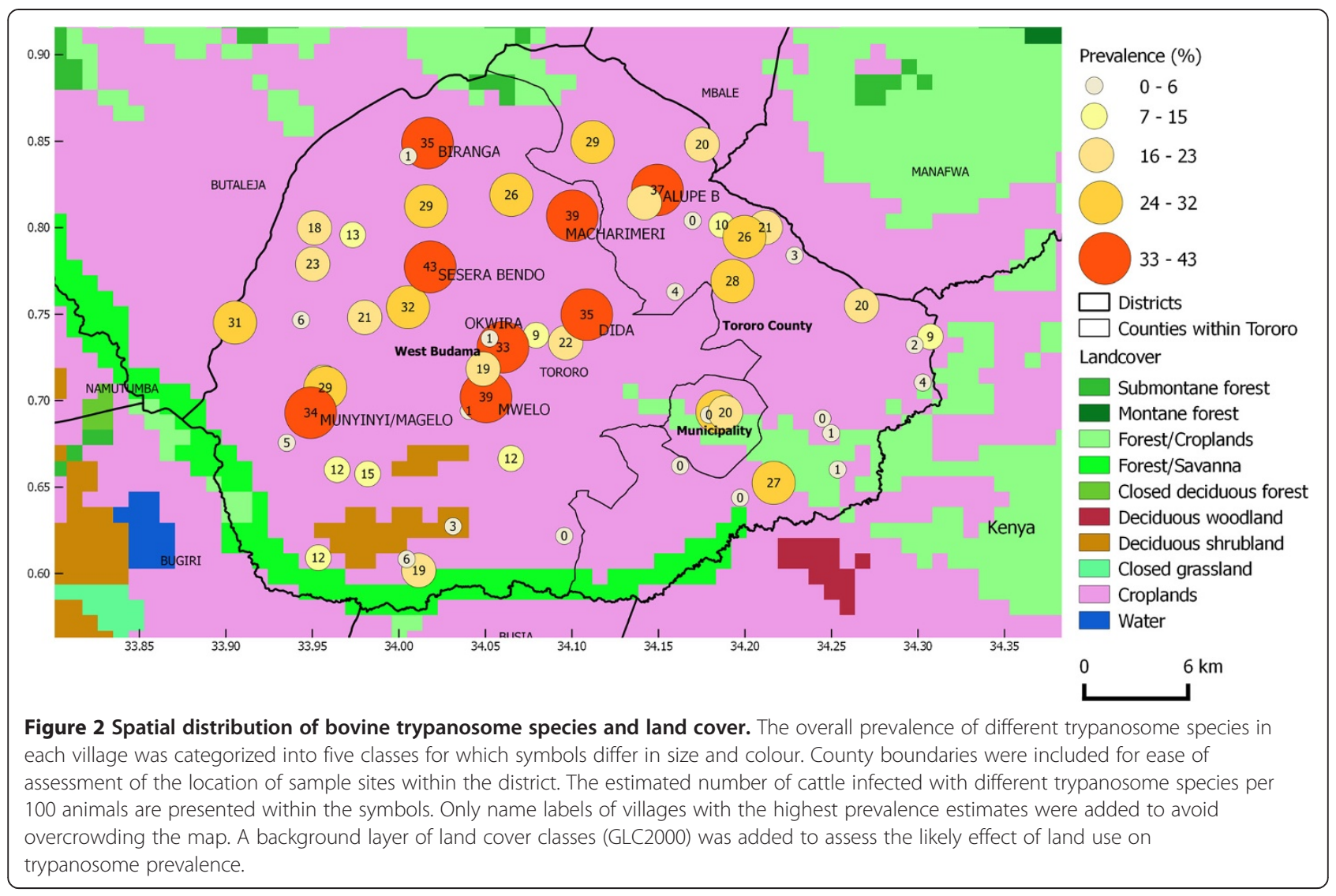

aside, mechanical transmission may explain why $T$. vivax was detected in most sampled villages. T. vivax undergoes a short life cycle in the proboscis of tsetse [42-44] and a fast build-up of parasitaemia in mammalian hosts [45] which may contribute to T.vivax detection in cattle.

Prevalences of T. congolense, T.b. brucei and T. b. rhodesiense in Tororo District were lower than observed for T. vivax. However, T. c. savannah was detected in slightly above half (53\%) of all the herds (villages) screened. The wider distribution of T. c. savannah in Tororo District herds may be as a result of re-invasion of G.pallidipes in Tororo, associated with risk of transmission of T. c. savannah [38].

T. congolense and the haemorrhagic strain of T.vivax are the most pathogenic trypanosome species of cattle in East Africa causing an acute and fatal disease compared to a more chronic form of AAT caused by other bovine trypanosome species and strains $[34,46]$. That $T$. congolense infections progress to a fatal disease rapidly, demanding treatment, may explain why $T$. congolense was detected in low prevalences in apparently healthy animals screened in the 57 villages of Tororo [47]. The very high prevalence and wide distribution of $T$. congolense and T.vivax in Tororo District indicates that these highly pathogenic trypanosome species continue to constrain livestock production calling for sustainable trypanosomiasis control measures.

T. $b$ brucei and T. $b$. rhodesiense were detected in low individual species and herd prevalences. The very low prevalence $(0.03 \%)$ of $T . b$. rhodesiense in cattle indicates that there still remains a low risk of transmission of $T . b$. rhodesiense from cattle to humans. This is especially so in the two villages of Chawolo-Sironga B and Kadanya where two cattle blood samples were found positive for T. $b$. rhodesiense, one sample from each village. Given that ITS1-PCR has slightly lower sensitivity (95\%) to T.brucei s.l. than the species specific PCR ( 100\%) T.brucei s.l. may have been under detected by ITS1-PCR [48-50].

The last outbreak of sleeping sickness in Tororo District was in 2000/2001 [50]. Since then, there have not been reports of the human disease in the district. That T. b. rhodesiense was detected only in 2 out of 6,054 cattle sampled shows that the cattle reservoir for this infection in Tororo District is persistent and is of concern. The presence of human infective $T . b$. rhodesiense animal carriers within isolated villages in Tororo District indicates that humans in these isolated villages remain at risk of acquiring infection given the abundance of tsetse flies [51]. 
Cattle are grazed communally in large herds (average of 106) in Tororo but at night are kept in smaller groups (average of 4) in night-shades or tethered around homesteads $[19,20,37]$. The number of animals per household is low typical of livestock holding in south-eastern Uganda. Boran and African short horn Zebu (Nkedi) hybrids and Nkedi are the major cattle breeds kept in Tororo District $[19,20,52]$. The male to female cattle ratio is high $(0.8)$ in Tororo, since farmers need to retain bulls (whole or neutered) for 3 years or more to provide draught power in these mixed crop-livestock systems [19,53]. Cattle over three years of age have been associated with a higher risk of infection and spread of human infective T.b rhodesiense [54]. Production systems that retain a very high proportion of cattle above 3 years of age pose a risk for zoonotic T.b. rhodesiense HAT transmission. Improving livestock health by controlling tsetse and trypanosomiasis will reduce HAT incidence, enhance livestock production and livestock-crop integration thereby reducing poverty and hunger $[17,55-57]$

The individual and herd prevalences reported in this study show that African trypanosomiasis remains a constraint to livestock production and livestock-crop integration in Tororo District despite farmer and local government-led tsetse and trypanosomiasis control efforts [36]. Lack of sustainability caused by insufficient follow-up, civil unrest and inadequate financing have resulted in failure of most tsetse control programs in Uganda [58]. Cattle as persistent reservoirs of human HAT should be treated to remove risk to poor communities in affected districts [6]. To prevent reinfection by tsetse control, the control methods used ought to be effective and sustainable. This requires that such methods are tailored to the limited budgets of poor rural livestock keepers and are effective against multiple endemic livestock diseases [59]. Control methods based on the use of restricted application of insecticides (RAP) on predilection sites for tsetse and/or ticks or spraying larger animals could serve to reduce the cost of RAP and offer added value of targeting ticks and biting flies making it easily adoptable for routine tsetse control [60-62].

\section{Conclusion}

African animal trypanosomiasis continues to be one of the main constraints to livestock production in Uganda. The current study indicates that the prevalence of different trypanosome species in Tororo District is still high despite government and farmer-led tsetse and trypanosomiasis control efforts. There is need to further intensify tsetse and trypanosomiasis control efforts in the district preferably by employing effective and sustainable tsetse and trypanosomiasis control methods. Such methods would need to be compatible to inelastic budgets of resource poor livestock keepers and be effective against most important endemic vector-borne diseases namely; tsetse and tick-borne diseases.

\section{Competing interests}

The authors hereby declare no competing interests. The sponsors had no role in the study design, data collection and analysis, decision to publish, or preparation of the manuscript.

\section{Authors' contributions}

$\mathrm{DM}, \mathrm{KP}, J \mathrm{H}, \mathrm{MT}$, SCW, JDK and CW conceived and designed this study. DM carried out blood sample collection and PCR analyses while DM and $\mathrm{JH}$ carried out statistical analyses. All authors participated in the manuscript write-up, read the final version and approved it to be submitted for publication.

\section{Acknowledgements}

The research leading to these results has received funding from the European Union's Seventh Framework Program (FP7/2007-2013) under grant agreement $n^{\circ} 221948$, ICONZ (Integrated Control of Neglected Zoonoses) to CW and JDK and Carnegie-Makerere University Next Generation of African Academics under grant number NGAA-2010-2012 to MD. Authors wish to acknowledge the assistance of Tororo District Veterinary officer; Dr. Tegule Mukonge and that of the other Tororo District Department of Production staff for the assistance they offered during collection of cattle blood samples. We also acknowledge Ward Bryssinckx of Avia-GIS, Belgium for helping with use of ArcMap software in general mapping and spatial data analysis.

\section{Author details}

${ }^{1}$ Department of Biomolecular and Biolaboratory Sciences, School of Biosecurity, Biotechnical and Laboratory Sciences, College of Veterinary Medicine Animal Resources and Biosecurity, Makerere University, P.O. Box 7062, Kampala, Uganda. ${ }^{2}$ Division of Infection \& Pathway Medicine, Centre for Infectious Diseases, School of Biomedical Sciences, College of Medicine and Veterinary Medicine, The University of Edinburgh, Chancellor's Building, 49 Little France Crescent, Edinburgh EH16 4SB, UK. ${ }^{3}$ Department of Public Health and Epidemiology, Swiss Tropical Institute, Socinstrasse 57, CH-4002 Basel, Switzerland. ${ }^{4}$ University of Basel, Petersplatz 1, 4003 Basel, Switzerland. ${ }^{5}$ Royal (Dick) School of Veterinary Studies, The University of Edinburgh, Edinburgh EH25 9RG, UK. 'Department of Biosecurity, Ecosystems \& Veterinary Public Health, School of Biosecurity, Biotechnical and Laboratory Sciences, College of Veterinary Medicine Animal Resources and Biosecurity, Makerere University, P.O. Box 7062, Kampala, Uganda. ${ }^{7}$ Department of Pharmacy, Clinical and Comparative Medicine, School of Veterinary Medicine and Animal Resources, College of Veterinary Medicine Animal Resources and Biosecurity, Makerere University, P.O. Box 7062, Kampala, Uganda.

Received: 27 September 2014 Accepted: 11 December 2014 Published online: 23 December 2014

\section{References}

1. Murray M, Gray AR: The current situation on animal trypanosomiasis in Africa. Prev Vet Med 1984, 2:23-30.

2. Swallow B: Impacts of African animal trypanosomosis on migration, livestock and crop production. Nairobi, ILRI 1998:1-19.

3. Clarkson MJ: Trypanosomes. Vet Parasitol 1976, 2(1):9-29.

4. Magona JW, Mayende JS, Olaho-Mukani W, Coleman PG, Jonsson NN, Welburn SC, Eisler MC: A comparative study on the clinical, parasitological and molecular diagnosis of bovine trypanosomosis in Uganda. Onderstepoort $J$ Vet Res 2003, 70(3):213-218.

5. Shaw AP: Assessing the economics of animal trypanosomosis in Africa-history and current perspectives. Onderstepoort J Vet Res 2009, 76(1):27-32.

6. Fevre EM, Coleman PG, Odiit MD, Magona J, Welburn SC MEJ: Woolhouse The origins of a new sleeping sickness outbreak (caused by Trypanosoma brucei infection) in eastern Uganda. Lancet 2001, 358:625-628.

7. Wardrop N, Fevre EM, Atkinson P, Welburn SC: The dispersal ecology of Rhodesian sleeping sickness following its introduction to a new area. PLoS Negl Trop Dis 2013, 7(10):e2485.

8. Selby R, Bardosh K, Waiswa C, Welburn SC: Cattle movements and trypanosomes: Restocking efforts and the spread of Rhodesian sleeping sickness in post-conflict Uganda. Parasit Vectors 2013, 6:281.

9. Desquesnes M, Dia ML: Mechanical transmission of Trypanosoma vivax in cattle by the African tabanid Atylotus fuscipes. Vet Parasitol 2004, 119(1):9-19. 
10. Welburn SC, Picozzi K, Fevre EM, Coleman PG, Odiit M, Carrington M, Maudlin I: Identification of human infective trypanosomes in animal reservoir of sleeping sickness in Uganda by means of serum-resistanceassociated (SRA) gene. Lancet 2001, 358:2017-2019.

11. Picozzi K, Fevre EM, Odiit M, Carrington M, Eisler MC, Maudlin I, Welburn SC: Sleeping sickness in Uganda: a thin line between two fatal diseases. BMJ 2005, 331(7527):1238-1241.

12. Waiswa C, Olaho-Mukani W, Katunguka-Rwakishaya E: Domestic animals as reservoirs for sleeping sickness in three endemic foci in south-eastern Uganda. Ann Trop Med Parasitol 2003, 97(2):149-155.

13. Minjauw B, McLeod A: Tick-borne diseases and poverty. The impact of ticks and tick- borne diseases on the livelihood of small-scale and marginal livestock owners in India and eastern and southern Africa. Research report, DFID Animal Health Programme Centre for Tropical Veterinary Medicine, University of Edinburgh, UK

14. Perry B, Sones K: Poverty reduction through animal health. Science 2007, 315(5810):333-334.

15. Kabayo JP: Aiming to eliminate tsetse from Africa. Trends Parasitol 2002, 18(11):473-475.

16. Hotez PJ: The neglected tropical diseases and their devastating health and economic impact on the member nations of the Organisation of the Islamic Conference. PLoS Negl Trop Dis 2009, 3(10):e539.

17. Hursey BSJ: Slingernbergh: The tsetse fly and its effects on agriculture in sub-Saharan Africa. World Anim Rev 1995, 84-85:67-73.

18. Wardrop NA, Fèvre EM, Atkinson PM, Kakembo A, Welburn SC: An exploratory GIS-based method to identify and characterise landscapes with an elevated epidemiological risk of Rhodesian human African trypanosomiasis. BMC Infect Dis 2012, 12:316.

19. Muhanguzi D, Picozzi K, Hatendorf J, Thrusfield M, Welburn SC, Kabasa JD, Waiswa C: Prevalence and spatial distribution of Theileria parva in cattle under crop-livestock farming systems in Tororo District, Eastern Uganda. Parasit Vectors 2014, 7:91

20. Muhanguzi D, Picozzi K, Hatendorf J, Thrusfield M, Welburn SC, Kabasa JD, Waiswa C: Collateral benefits of restricted insecticide application for control of African trypanosomiasis on Theileria parva in cattle: a randomized controlled trial. Parasit Vectors 2014, 7(1):432.

21. Anonymous: The National Livestock Census: A summary report of the national livestock census. Kampala: Uganda Bureau of Statistics: Ministry of Agriculture Animal Industry and Fisheries Kampala, 2009:41.

22. Bennett $S$, Woods T, Liyanage WM, Smith DL: A simplified general method for cluster-sample surveys of health in developing countries. World Health Stat Q 1991, 44(3):98-106.

23. Thrusfield M: Veterinary Epidemiology. 3rd edition. Oxford: Blackwell science; 2007.

24. Farid MN, Frerichs RR: CSurvey, version 2.0. Department of Epidemiology, University of California, Los Angels (UCLA), Los Angeles. 2007.

25. Bohning D, Greiner M: Prevalence estimation under heterogeneity in the example of bovine trypanosomosis in Uganda. Prev Vet Med 1998, 36(1):11-23

26. Orjuela J, Navarrete M, Betancourst A, Roqueme L, Cortez E, Morrison RB: Salud y productividad en bovines de la costa norte en Colombia. 2. Hallazgos, serologicos, bacteriologicos y parasitologicos. World Anim Rev 1991, 69:7-14

27. Dhalwa J: Animal Health and Production Constraints in Traditional Farming Systems in Mbarara District, Uganda. University of Reading, UK; 1995.

28. Cochran WG: Sampling Techniques. 3rd edition. New York: Wiley; 1977.

29. Picozzi K, Tilley A, Fèvre E, Coleman P, Magona J, Odiit M, Eisler M, Welburn S: The diagnosis of trypanosome infections: applications of novel technology for reducing disease risk. Afr J Biotechnol 2002, 1(2):39-45.

30. Ahmed HA, MacLeod ET, Hide G, Welburn SC, Picozzi K: The best practice for preparation of samples from FTA(R)cards for diagnosis of blood borne infections using African trypanosomes as a model system. Parasit Vectors 2011, 4:68.

31. Becker S, Franco JR, Simarro PP, Stich A, Abel PM, Steverding D: Real-time PCR for detection of Trypanosoma brucei in human blood samples. Diagn Microbiol Infect Dis 2004, 50(3):193-199.

32. Niiru ZK, Constantine CC, Guya S, Crowther J, Kiragu JM, Thompson RC, Davila AM: The use of ITS1 rDNA PCR in detecting pathogenic African trypanosomes. Parasitol Res 2005, 95(3):186-192.

33. Picozzi K, Carrington M, Welburn SC: A multiplex PCR that discriminates between Trypanosoma brucei brucei and zoonotic T. b. rhodesiense. Exp Parasitol 2008, 118(1):41-46.
34. Masiga DK, Smyth AJ, Hayes P, Bromidge TJ, Gibson WC: Sensitive detection of trypanosomes in tsetse flies by DNA amplification. Int J Parasitol 1992, 22(7):909-918.

35. Magona JW, Walubengo J, Odiit M, Okedi LA, Abila P, Katabazi BK, Gidudu AM, Olaho-Mukani W: Implications of the re-invasion of Southeast Uganda by Glossina pallidipes on the epidemiology of bovine trypanosomosis. Vet Parasitol 2005, 128(1-2):1-9.

36. Coleman PG, Welburn SC: Are fitness costs associated with resistance to human serum in Trypanosoma brucei rhodesiense? Trends Parasitol 2004, 20:311-315

37. Muhanguzi D, Picozzi K, Hatendorf J, Thrusfield M, Welburn SC, Kabasa JD, Waiswa C: Improvements on restricted insecticide application protocol for control of human and animal african trypanosomiasis in eastern Uganda. PLoS Negl Trop Dis 2014, 8(10):e3284.

38. Moloo SK, Kutuza SB, Boreham PF: Studies on Glossina pallidipes. G. fuscipes fuscipes and $\mathrm{G}$. brevipalpis in terms of the epidemiology and epizootiology of trypanosomiases in south-eastern Uganda. Ann Trop Med Parasitol 1980, 74(2):219-237.

39. Okoth JO: Observation on the composition of Glossina population at Lugala, south Busoga district, Uganda. East Afr Med J 1980, 57:332-336.

40. Okoth JO: Further observations on the composition of glossina population at Lugala, South Busoga, Uganda. East Afr Med J 1982, 59:582-584.

41. Moloo S: Interacting factors in the epidemiology of trypanosomiasis in an endemic/enzootic region of Uganda and its contiguous area of Kenya. Insect SC Appl 1980, 1(01):117-121.

42. Gardiner PR, Wilson AJ: Trypanosoma (Duttonefla) vivax. Parasitol Today 1987, 3(2):49-52.

43. Jones TW, Davila AM: Trypanosoma vivax-out of Africa. Trends Parasitol 2001, 17(2):99-101.

44. Jefferies D, Helfrich MP, Molyneux DH: Cibarial infections of Trypanosoma vivax and T. congolense in Glossina. Parasitol Res 1987, 73(4):289-292.

45. Osório AL, Madruga CR, Desquesnes M, Soares CO, Ribeiro LR, Costa SC: Trypanosoma (Duttonella) vivax: its biology, epidemiology, pathogenesis, and introduction in the New World - a review. Mem Inst Oswaldo Cruz 2008, 103:1-13.

46. Magona JW, Walubengo J, Odimin JT: Acute haemorrhagic syndrome of bovine trypanosomosis in Uganda. Acta Trop 2008, 107(2):186-191.

47. Leak SGA, Rowlands GJ: The dynamics of trypanosome infections in natural populations of tsetse (Diptera: Glossinidae) studied using wing-fray and ovarian ageing techniques. Bull Entomol Res 1997, 87(03):273-282.

48. Cox A, Tosas O, Tilley A, Picozzi K, Coleman P, Hide G, Welburn S: Constraints to estimating the prevalence of trypanosome infections in East African zebu cattle. Parasit Vectors 2010, 3:82.

49. Moser DR, Kirchhoff LV, Donelson JE: Detection of Trypanosoma cruzi by DNA amplification using the polymerase chain reaction. $J$ Clin Microbiol 1989, 27(7):1477-1482.

50. Ahmed HA, Picozzi K, Welburn SC, MacLeod ET: A comparative evaluation of PCR- based methods for species- specific determination of African animal trypanosomes in Ugandan cattle. Parasit Vectors 2013, 6(1):316.

51. Odiit M, Bessell PR, Fevre EM, Robinson T, Kinoti J, Coleman PG, Welburn SC, McDermott J, Woolhouse ME: Using remote sensing and geographic information systems to identify villages at high risk for rhodesiense sleeping sickness in Uganda. Trans R Soc Trop Med Hyg 2006, 100(4):354-362.

52. Magona JW, Walubengo J, Odimim JJ: Differences in susceptibility to trypanosome infection between Nkedi Zebu and Ankole cattle, under field conditions in Uganda. Ann Trop Med Parasitol 2004, 98(8):785-792.

53. Ocaido M, Otim CP, Okuna NM, Erume J, Ssekitto C, Wafula RZO, Kakaire D, Walubengo J, Monrad J: Socio-economic and livestock disease survey of agro-pastoral communities in Serere County, Soroti District, Uganda. Livest Res Rural Dev 2005, 17:93.

54. von Wissmann B, Fyfe J, Picozzi K, Hamill L, Waiswa C, Welburn SC: Quantifying the association between bovine and human trypanosomiasis in newly affected sleeping sickness areas of Uganda. PLOS Negl Trop Dis 2014, 8(6):e2931.

55. Murray M, Gray A: The current situation on animal trypanosomiasis in Africa. Prev Vet Med 1984, 2(1):23-30.

56. Swallow BM: Impacts of Trypanosomiasis on African Agriculture. Rome: FAO; 1999.

57. Machila N, Emongor R, Shaw AP, Welburn SC, McDermott J, Maudlin I, Eisler MC A community education intervention to improve bovine trypanosomiasis knowledge and appropriate use of trypanocidal drugs on smallholder farms in Kenya. Agr Syst 2007, 94(2):261-272. 
58. Allsopp R: Options for vector control against trypanosomiasis in Africa. Trends Parasitol 2001, 17(1):15-19.

59. Okello A, Welburn S, Kabasa JD, Waiswa C, Rannaleet A, Mitchell M, Semakula L: Stamp Out Sleeping Sickness (SOS): An Innovative One Health Approach to Neglected Zoonotic Disease in Uganda. Ecohealth 2011, 7:S72-S72.

60. Hargrove JW, Ouifki R, Kajunguri D, Vale GA, Torr SJ: Modeling the control of trypanosomiasis using trypanocides or insecticide-treated livestock. PLoS Negl Trop Dis 2012, 6(5):e1615.

61. Torr SJ, Maudlin I, Vale GA: Less is more: restricted application of insecticide to cattle to improve the cost and efficacy of tsetse control. Med Vet Entomol 2007, 21(1):53-64.

62. Kajunguri D, Hargrove JW, Ouifki R, Mugisha JY, Coleman PG, Welburn SC: Modelling the use of insecticide-treated cattle to control tsetse and Trypanosoma brucei rhodesiense in a multi-host population. Bull Math Biol 2014, 76(3):673-696.

\section{Submit your next manuscript to BioMed Central and take full advantage of:}

- Convenient online submission

- Thorough peer review

- No space constraints or color figure charges

- Immediate publication on acceptance

- Inclusion in PubMed, CAS, Scopus and Google Scholar

- Research which is freely available for redistribution 